\title{
PTH(1-34) activates the migration and adhesion of BMSCs through the rictor/mTORC2 pathway
}

\author{
ZHONG LV ${ }^{1,2^{*}}$, AIKEREMUJIANG MUHEREMU ${ }^{3 *}, \mathrm{XIAOCHUN} \mathrm{BAI}^{2,4}$, \\ XUENONG ZOU ${ }^{2,4}$, TAO LIN ${ }^{5}$ and BAILING $\mathrm{CHEN}^{2,4}$ \\ ${ }^{1}$ Department of Orthopedics, Guangzhou Panyu Central Hospital; ${ }^{2}$ Guangdong Provincial Key Laboratory of \\ Orthopedics and Traumatology, The First Affiliated Hospital of Sun Yat-sen University, Guangzhou, Guangdong 510080; \\ ${ }^{3}$ Department of Orthopedics, Peking University Third Hospital, Beijing 100191; ${ }^{4}$ Department of Spine Surgery, \\ The First Affiliated Hospital of Sun Yat-sen University, Guangzhou, Guangdong 510080; ${ }^{5}$ Department of Orthopedics, \\ Zhujiang Hospital of Southern Medical University, Guangzhou, Guangdong 510280, P.R. China
}

Received March 8, 2020; Accepted July 9, 2020

DOI: $10.3892 /$ ijmm.2020.4754

\begin{abstract}
The ability of intermittent parathyroid hormone (1-34) [PTH(1-34)] treatment to enhance bone-implant osseointegration was recently demonstrated in vivo. However, the mechanisms through which PTH (1-34) regulates bone marrow-derived stromal cells (BMSCs) remain unclear. The present study thus aimed to investigate the effects of PTH(1-34) on the migration and adhesion of, and rictor/mammalian target of rapamycin complex 2 (mTORC2) signaling in BMSCs. In the present study, BMSCs were isolated from Sprague-Dawley
\end{abstract}

Correspondence to: Dr Bailing Chen or Dr Xiaochun Bai, Guangdong Provincial Key Laboratory of Orthopedics and Traumatology, The First Affiliated Hospital of Sun Yat-sen University, 58 Zhongshan 2nd Road, Guangzhou, Guangdong 510080, P.R. China

E-mail: chenbl2012@163.com

E-mail: xiaochunbai@aliyun.com

*Contributed equally

Abbreviations: BMSCs, bone marrow-derived stromal cells; PTH, parathyroid hormone; rhPTH, recombinant human parathyroid hormone; IGF-I, insulin-like growth factor-I; PDLSCs, periodontal ligament stem cells; mTOR, mammalian target of rapamycin; PIKK, phosphatidylinositol kinase-related kinase; mTORC, mammalian target of rapamycin complex; $\mathrm{PKC} \alpha$, protein kinase $\mathrm{C} \alpha$; DMEM/F12, Dulbecco's modified Eagle's medium F-12; GM, growth medium; BSA, bovine serum albumin; PVDF, polyvinylidene fluoride; ICAM-1, intercellular adhesion molecule 1; FN, fibronectin; RT-qPCR, reverse transcription-quantitative polymerase chain reaction; DEPC, diethyl pyrocarbonate; one-way ANOVA, one-way analysis of variance; MSC, mesenchymal stem cell; CCR2, chemokine receptor 2; CFU-F, colony-forming units-fibroblastic; FDL, flexor digitorum longus

Key words: $\mathrm{PTH}, \mathrm{BMSCs}$, rictor/mTORC2 pathway, migration, adhesion rats treated with various concentrations of PTH(1-34) for different periods of time. PTH(1-34) treatment was performed with or without an mTORC1 inhibitor (20 nM rapamycin) and mTORC1/2 inhibitor (10 $\mu \mathrm{M}$ PP242). Cell migration was assessed by Transwell cell migration assays and wound healing assays. Cell adhesion and related mRNA expression were investigated through adhesion assays and reverse transcription-quantitative polymerase chain reaction (RT-qPCR), respectively. The protein expression of chemokine receptors (CXCR4 and CCR2) and adhesion factors [intercellular adhesion molecule 1 (ICAM-1), fibronectin and integrin $\beta 1$ ] was examined by western blot analysis. The results revealed that various concentrations $(1,10,20,50$ and $100 \mathrm{nM})$ of PTH(1-34) significantly increased the migration and adhesion of BMSCs, as well as the expression of CXCR4, CCR2, ICAM-1, fibronectin and integrin $\beta 1$. In addition, the p-Akt and p-S6 levels were also upregulated by $\mathrm{PTH}(1-34)$. BMSCs subjected to mTORC1/2 signaling pathway inhibition or rictor silencing exhibited a markedly reduced PTH-induced migration and adhesion, while no such effect was observed for the BMSCs subjected to mTORC1 pathway inhibition or raptor silencing. These results indicate that $\mathrm{PTH}(1-34)$ promotes BMSC migration and adhesion through rictor/mTORC2 signaling in vitro. Taken together, the results of the present study reveal an important mechanism for the therapeutic effects of PTH(1-34) on bone-implant osseointegration and suggest a potential treatment strategy based on the effect of PTH(1-34) on BMSCs.

\section{Introduction}

Bone implant surgery is required for a variety of reasons, such as bone degenerative changes, trauma, tumors and deformities. However, whether the implant can remain stably fixed for a long period of time directly affects the surgical outcome and post-operative rehabilitation of the patient. Some studies have demonstrated that the poor bone integration of implants is the major cause of implant loosening $(1,2)$. Ideal implant-bone integration involves a complex reaction between the bone and the implant surface. Recent studies have also indicated that the migration and adhesion of functional cells to the surface 
of an implant plays a pivotal role in the process of implant osseointegration $(3,4)$. Osteoblasts are considered to be derived from the osteoblastic differentiation of multipotent bone marrow-derived stromal cells (BMSCs), and the effects of BMSC osteoblastic differentiation on the surface of the implant has been investigated in previous studies (5-8).

Parathyroid hormone (PTH) is secreted by the parathyroid gland and can regulate calcium and phosphorus metabolism, promote osteoblast activity and accelerate bone transformation. Recombinant human PTH(1-34) [rhPTH(1-34)], which has been approved for the treatment of osteoporosis, can promote bone formation, increase bone strength and reduce the risk of fracture, unlike other drugs used in the treatment of osteoporosis that suppress bone resorption $(9,10)$. The effects of PTH on bone anabolism and catabolism depend on the dosage and duration of administration. Constant PTH stimulation can activate protein cleavage and degradation pathways and improve bone turnover. However, the intermittent use of PTH has been shown to promote bone anabolism in some animal experiments (11).

Despite extensive studies, the mechanisms through which PTH promotes bone anabolism remain unclear. A potential mechanism is attributed to the increased proliferation of osteoblasts via the expression of insulin insulin-like growth factor-I (IGF-I) and the differentiation of osteoprogenitor cells in the bone marrow. The results of a recent study suggested that PTH can regulate the migration and osteogenic differentiation of human periodontal ligament stem cells (PDLSCs). The results of that study demonstrated that PTH can activate the adhesion of multipotent bone marrow stromal precursors, and this observation may represent an early stage of the PTH-induced osseointegration response in bone (12).

Mammalian target of rapamycin (mTOR) is an atypical serine/threonine protein kinase and a member of the phosphatidylinositol kinase-related kinase (PIKK) protein family. The mTOR pathway can regulate cell metabolism, migration, self-renewal and autophagy $(13,14)$. There are two different mTOR complexes in mammalian cells: mTOR complex 1 (mTORC1) and mTOR complex 2 (mTORC2). In recent years, the key role of mTORC2 in regulating cell migration, adhesion and cytoskeletal reorganization has been confirmed (15-17). In mammalian cells, mTORC2 regulates the orderly assembly of the actin cytoskeleton through protein kinase $\mathrm{C} \alpha(\mathrm{PKC} \alpha)$ (18). Sen et al (19) observed that following physical stimulation intervention in mesenchymal stem cells (MSCs), the expression of F-actin and vinculin increased and involved the mTORC2 pathway. In addition, previous studies have indicated that mTORC2 is involved in the migration of colorectal cancer, osteosarcoma and bladder cancer cells (20-22).

Based on the above-mentioned findings, in the present study, it was hypothesized that $\mathrm{PTH}(1-34)$ can stimulate the migration and adhesion of BMSCs by activating the mTORC2 signaling pathway. Therefore, in order to further elucidate the cellular and molecular mechanisms through which PTH affects osteoimplant integration, the effects of $\mathrm{PTH}(1-34)$ on BMSC migration and adhesion and the potential role of mTORC2 signaling in mediating these effects were investigated.

\section{Materials and methods}

Isolation and culturing of BMSCs. A total of 20 male Sprague-Dawley rats (4-6 weeks old; 100-120 g) were purchased from the Experimental Animal Center of Sun Yat-Sen University for use in the present study. The rats were allowed to adapt to the housing conditions for 7 days, during which the rats were maintained under a 12-h light/dark cycle at $22^{\circ} \mathrm{C}$ with free access to food and water $(23,24)$. The present study was approved by the Animal Care Committee of Sun Yat-Sen University [no. (2014)52] and was performed in accordance with the guidelines for the use of laboratory animals. In summary, BMSCs were harvested from the femoral and tibial medullary cavities by flushing with a $5 \mathrm{ml}$ syringe and suspended in Dulbecco's modified Eagle medium F-12 (DMEM/F12) growth medium (GM). The cells were cultured in a humidified incubator at $37^{\circ} \mathrm{C}$ under an atmosphere with $5 \% \mathrm{CO}_{2}$ and the third generation of BMSCs were used in the experiments.

Wound healing assay. A wound healing assay was performed in 6-well plates. BMSCs were seeded in 6-well plates at a density of $5 \times 10^{5}$ cells per well. The cells were deprived of serum for $24 \mathrm{~h}$ and then scratched with a $100-\mu \mathrm{l}$ pipette tip. Subsequently, various treatments were applied, including PP242 (10 $\mu \mathrm{M} / \mathrm{l})$, PTH (1-34) (10 nM/l), PP242 and PTH(1-34), rapamycin $(20 \mathrm{nM})$, rapamycin and $\mathrm{PTH}(1-34)$, raptor(-), raptor(-) and PTH(1-34), rictor(-), and rictor(-) and PTH (1-34). In the PTH group, BMSCs were exposed to $10 \mathrm{nM} \mathrm{PTH(1-34)}$ in DMEM medium for the first $4 \mathrm{~h}$ of each $8 \mathrm{~h}$ cycle and then washed with phosphate-buffered saline (PBS) and the process was repeated for the subsequent $20 \mathrm{~h}$. The surface scratches were monitored using a microscope (Zeiss AG) at 0 and $24 \mathrm{~h}$.

Lentivirus production. siRNA targeting rat rictor and raptor lentivirus were procured from Shanghai GeneChem Co., and the target sequences were as follows: (sirictor, GTCCAG AGAATCACAGAGAAA; siraptor, CGGGTCCTCTTC CACTATAA; siControl, CGCTTCCGCGGCCCGTTCAA). The 400-position transfection mixture containing sirictor or siraptor, VSVG, PAX2 and transfection reagent polyethyleneimine (Polysciences) in DMEM, was incubated at room temperature for $15 \mathrm{~min}$, and then added to BMSCs $\left(5 \times 10^{5}\right.$ cells per well). Cells were cultured in a $37^{\circ} \mathrm{C}$ virus incubator for $48 \mathrm{~h}$. The transfected cells were selected and incubated in puromycin at $3 \mu \mathrm{g} / \mathrm{ml}$ for $24 \mathrm{~h}$. The transfection efficiency was determined by western blot analysis of the control group, siCtrl group, siraptor groups and sirictor groups.

Transwell migration assay. Transwell migration assays were performed in 24-well plates. BMSCs were serum-starved for $24 \mathrm{~h}$ before being seeded into the upper chambers of a Transwell plate and cultured with serum-free medium at a concentration of $1 \times 10^{5}$ cells per well. In the lower chambers, $300 \mu 1$ of medium with PP242 (10 $\mu \mathrm{M} / \mathrm{l})$, PTH (1-34) $(10 \mathrm{nM} / \mathrm{l})$, PP242 and PTH(1-34), rapamycin (20 $\mathrm{nM})$, rapamycin and $\mathrm{PTH}(1-34)$, raptor(-), raptor(-) and $\mathrm{PTH}(1-34)$, rictor(-), and rictor(-) and PTH(1-34) were added. In the containing PTH group, cells were exposed to $10 \mathrm{nM}$ PTH(1-34) in DMEM medium for the first $4 \mathrm{~h}$ of each 8 -h cycle and the process 
Table I. Gene primers used for RT-qPCR.

\begin{tabular}{|c|c|c|}
\hline Gene & Primer & Sequence \\
\hline \multirow[t]{2}{*}{ CXCR-4 } & Forward & 5'-GGCTGACCTCTTTGT-3' \\
\hline & Reverse & 5'-GTTTCCTTCGCCTTTGAC-3' \\
\hline \multirow[t]{2}{*}{ CCR-2 } & Forward & 5'-GGAATCTTCTTCATTATCCTCCTGAC-3' \\
\hline & Reverse & 5'-TGACTACACTTGTTATTACCCCAAAGG-3' \\
\hline \multirow[t]{2}{*}{ ICAM-1 } & Forward & 5'-TTGGGCATAGAGACCCCGTT-3' \\
\hline & Reverse & 5'-GCACATTGCTCAGTTCATACACC-3' \\
\hline \multirow[t]{2}{*}{ Fibronectin } & Forward & 5'-CGGTGGCTGTCAGTCAAAG-3' \\
\hline & Reverse & 5'-AAACCTCGGCTTCCTCCATAA-3' \\
\hline \multirow[t]{2}{*}{ Integrin $\beta 1$} & Forward & 5'-TGAATGTGAATGCCAAAGCGA-3' \\
\hline & Reverse & 5'-CAATGTCTACCAACACGCCC-3' \\
\hline \multirow[t]{2}{*}{$\beta$-actin } & Forward & 5'-GTCTGCCTTGGTAGTGGATAATG-3' \\
\hline & Reverse & 5'-TCGAGGACGCCCTATCATGG-3' \\
\hline
\end{tabular}

was repeated for the subsequent $20 \mathrm{~h}$. The 24 -well plates were then placed in an incubator at $37^{\circ} \mathrm{C}$ under an atmosphere with $5 \% \mathrm{CO}_{2}$. Migrated cells were fixed in $4 \%$ paraformaldehyde for $15 \mathrm{~min}$ and stained with crystal violet for $30 \mathrm{~min}$ at room temperature. The migration of the BMSCs was monitored using a microscope (DMI3000 B; Leica). Subsequently, 5 random microscopic fields at a $\times 20$ magnification were selected to quantify the migrated cells. All experiments were repeated 3 times.

Adhesion assay. For this assay, 96-well plates were pre-coated with $10 \mu \mathrm{g} / \mathrm{ml}$ fibronectin (FN; $70 \mu \mathrm{l}$ per well), washed 3 times in PBS at $4^{\circ} \mathrm{C}$, blocked with $1 \%$ bovine serum albumin (BSA) for $1 \mathrm{~h}$ at $37^{\circ} \mathrm{C}$, and then washed 3 times with PBS. The cells to be examined were cultured to the logarithmic growth phase, digested and suspended in serum-free medium, counted with a hemocytometer, adjusted to a concentration of $5 \times 10^{5} / \mathrm{ml}$, and then inoculated into a fibronectin-coated 96-well plate. Each well contained 5,000 cells, and the experimental groups and control groups included 3 duplicate wells. After incubating the plates for $1 \mathrm{~h}$ at $37^{\circ} \mathrm{C}$, PBS was used to wash away unadhered cells. Subsequently, $100 \mu 1$ of methanol were added to each well, and the cells were fixed in $4 \%$ paraformaldehyde for $15 \mathrm{~min}$. Giemsa dye solution $(100 \mu \mathrm{l})$ was then added to each well for $15 \mathrm{~min}$ at room temperature, and the cells were washed with PBS. A total of 5 random fields were selected to count the number of adherent cells.

Western blot analysis. Western blot analysis was performed using standard techniques. Following 2 days of the treatment with $2 \mathrm{ml}$ various concentrations $(1,10,20,50$ and $100 \mathrm{nM})$ of PTH and 2 inhibitors (20 nM rapamycin and $10 \mu \mathrm{M}$ PP242), BMSCs were lysed in $50 \mu \mathrm{l}$ of protein extraction reagent (M-PER) (BestBio) and protease inhibitor cocktail. The protein samples were harvested following centrifugation for $15 \mathrm{~min}\left(12,000 \times \mathrm{g}, 4^{\circ} \mathrm{C}\right)$ and boiled for $5 \mathrm{~min}$ total protein concentration was determined using a NanoDrop 2000 spectrophotometer. Equal volumes $(20 \mu \mathrm{l})$ of the samples were separated via $10 \%$ SDS-PAGE and subsequently transferred to polyvinylidene fluoride (PVDF) membranes. The membranes were blocked with 5\% non-fat dry milk and then incubated overnight at $4{ }^{\circ} \mathrm{C}$ with primary antibodies specific for rabbit anti-phosphorylated S6 (p-S6) monoclonal antibody (mAb; 1:2,000; cat. no. 4858, Cell Signaling Technology, Inc.), rabbit anti-S6 (mAb; 1:2,000; cat. no. 2217, Cell Signaling Technology, Inc.), rabbit anti-CXCR4 (PcAb; 1:2,000; cat. no. PA1-22486, Invitrogen; Thermo Fisher Scientific, Inc.), rabbit anti-CCR2 (mAb; 1:1,000; cat. no. 12199, Cell Signaling Technology, Inc.), rabbit anti-intercellular adhesion molecule 1 (ICAM-1) (mAb; 1:1,000; cat. no. 67836, Cell Signaling Technology, Inc.), rabbit anti-FN (mAb; 1:2,000; cat. no. 45688, Abcam), rabbit anti-integrin $\beta 1$ (mAb; 1:1,000; cat. no. 34971, Cell Signaling Technology, Inc.), rabbit anti- $\beta$-actin (mAb; $1: 1,000$; cat. no. 4970) and anti-GAPDH (mAb; 1:1,000; cat. no. 5174) (Cell Signaling Technology, Inc.), followed by incubation with a alkaline phosphatase-conjugated goat anti-IgG (1:2,000, cat. no. 7054; Cell Signaling Technology, Inc.) for $1 \mathrm{~h}$ at room temperature. The immunoreactive proteins were visualized using a chemiluminescence kit (EMD Millipore), and band density analysis was carried out using Photoshop CS5 (Adobe Systems Incorporated, Inc.) and ImageJ 1.8.0 software (NIH).

Reverse transcription-quantitative polymerase chain reaction $(R T-q P C R)$. Total RNA was extracted from cultured cells following treatment with $2 \mathrm{ml}$ of various concentrations $(1,10$, 20, 50 and $100 \mathrm{nM}$ ) of PTH and 2 inhibitors (20 $\mathrm{nM}$ rapamycin and $10 \mu \mathrm{M}$ PP242) for 1 day using TRIzol reagent (Invitrogen; Thermo Fisher Scientific, Inc.). The RNA was then used for cDNA synthesis with the PrimeScript RT-PCR kit (Takara Biotechnology Co., Ltd.) in a $10 \mu \mathrm{l}$ reaction volume containing $0.5 \mu \mathrm{l}$ of PrimeScript RT Enzyme Mix I, $0.5 \mu \mathrm{l}$ of oligo dT primer, and $2.0 \mu \mathrm{l}$ of PrimeScript Buffer. Subsequently, $1 \mu \mathrm{l}$ of cDNA was used for qPCR in a $10 \mu \mathrm{l}$ reaction volume containing $0.3 \mu \mathrm{l}$ of the forward primer, $0.3 \mu \mathrm{l}$ of the reverse primer, $5 \mu \mathrm{l}$ of SYBR ${ }^{\circledR}$ Premix Ex Taq, and $3.4 \mu$ l of diethylpyrocarbonate (DEPC)-treated water. Each cDNA sample was assayed in triplicate. Fluorescence data was analyzed using a CFX96 ${ }^{\mathrm{TM}}$ Real-Time PCR Detection System (Bio-Rad Laboratories, Inc.). Gene expression levels were calculated using the $2^{-\Delta \Delta C q}$ method (25), and the data are presented as the fold change 
A

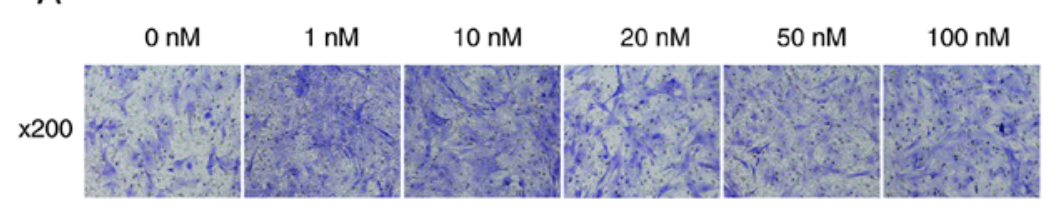

C

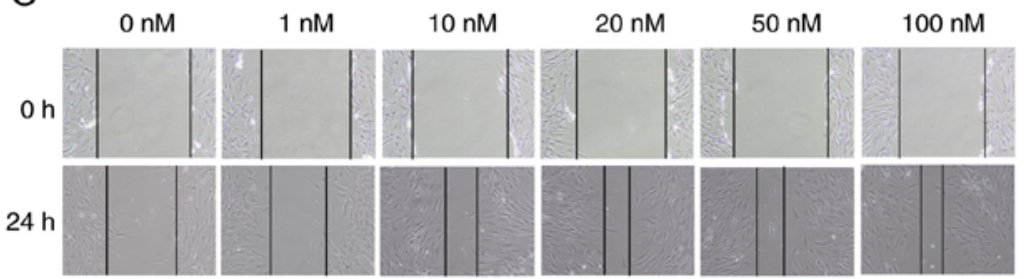

E

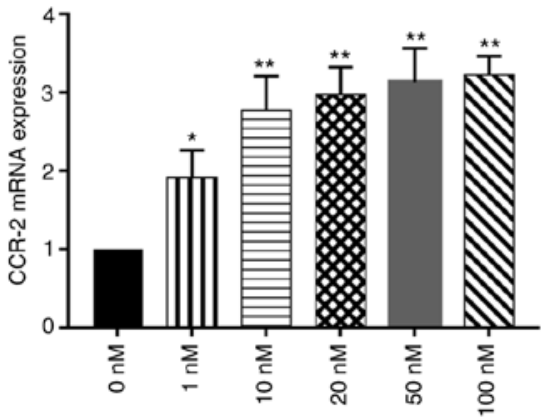

G

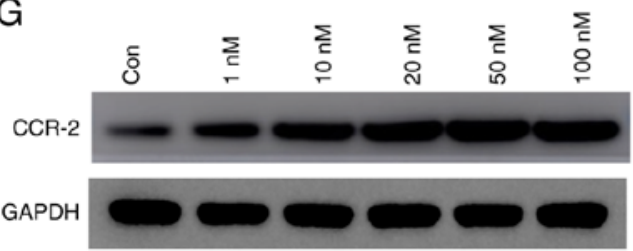

B
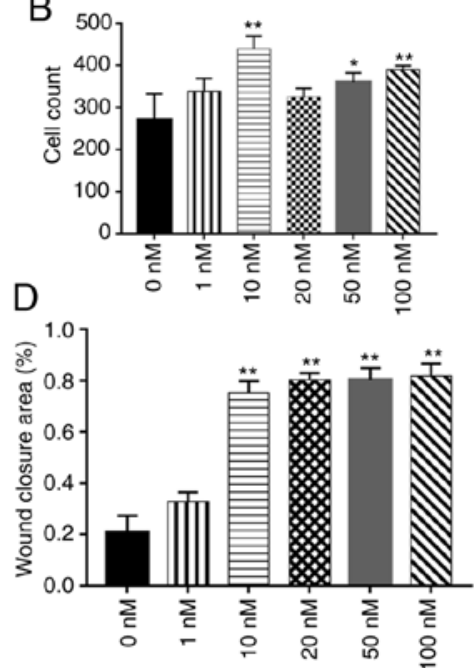

$\mathrm{F}$

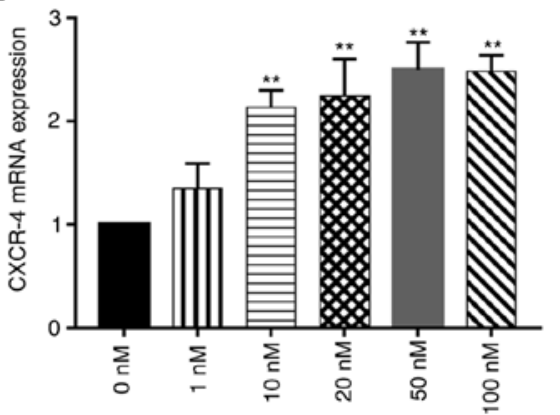

$\mathrm{H}$

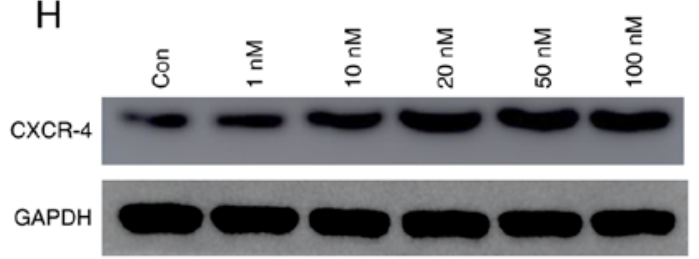

Figure 1. Effect of PTH(1-34) on BMSC migration. (A and B) BMSCs were seeded in the upper chamber of Transwell plates. The bottom wells were loaded with medium alone or medium containing 1, 10, 20, 50 or $100 \mathrm{nM}$ PTH (1-34) for $4 \mathrm{~h}$. The number of cells that migrated to the bottom wells was counted $24 \mathrm{~h}$ later. (C and D) Intermittent use of PTH(1-34) (1, 10, 20, 50 and $100 \mathrm{nM}$ ) (for the first $4 \mathrm{~h}$ of each 8 -h cycle). The cell layer was scratched with a $200 \mu 1$ sterile pipette tip, and the wound surface area was measured at the 0 and $24 \mathrm{~h}$ points. Cells cultured in medium were used as a blank control. The results are presented as the percentage of the scratch closure area. Scale bars, $100 \mu \mathrm{m}$; data are the means $\pm \mathrm{SD} ; \mathrm{n}=3{ }^{*} \mathrm{P}<0.05,{ }^{* * *} \mathrm{P}<0.01$ vs. control group. (E and $\left.\mathrm{F}\right) \mathrm{The}$ mRNA expression of chemokine receptors, including CXCR4 and CCR 2 , was measured by $\mathrm{RT}-\mathrm{qPCR}$. data are the means $\pm \mathrm{SD}$; $\mathrm{n}=3$; ${ }^{*} \mathrm{P}<0.05,{ }^{* *} \mathrm{P}<0.01$ vs. control group. ( $\mathrm{G}$ and $\mathrm{H}$ ) Western blot analysis of CXCR4 and CCR2 expression in BMSCs treated with various concentrations of PTH(1-34). BMSCs, bone marrow-derived stromal cells; PTH, parathyroid hormone.

relative to control samples. The primer sequences used for the RT-qPCR analyses of rat CXCR4, CCR2, ICAM-1, FN, integrin $\beta 1$ and $\beta$-actin are presented in Table $\mathrm{I}$.

Statistical analysis. Statistical analyses were performed using SPSS 22.0 software (SPSS, Inc.). The data are presented as the means \pm standard deviation. Differences between the quantitative values among multiple groups were analyzed with one-way analysis of variance (ANOVA) with the Tukey's test. $\mathrm{P}<0.05$ was considered to indicate a statistically significant difference.

\section{Results}

PTH(1-34) promotes the migration of BMSCs. It was observed that PTH(1-34) promoted BMSC migration, as shown by wound healing and Transwell migration assays.
The intermittent use of various concentrations of PTH(1-34) $(1,10,20,50$ and $100 \mathrm{nM})$ markedly enhanced the motility of the BMSCs in a concentration-dependent manner. In Transwell migration assays, the BMSCs treated with various concentrations of PTH(1-34) migrated to the lower chamber significantly more frequently than the BMSCs in the control group $(\mathrm{P}<0.01$; Fig. $1 \mathrm{~A}$ and $\mathrm{B})$. In addition, the 10, 20, 50 and $100 \mathrm{nM}$ concentrations of PTH(1-34) promoted BMSC migration compared to that observed with $0 \mathrm{nM}$ PTH(1-34), and no significant differences between the $1 \mathrm{nM}$ treatment and the control were observed, while intermittent PTH(1-34) treatment at various concentrations significantly increased the migration of the BMSCs $(\mathrm{P}<0.01)$ (Fig. 1C and D). In addition, $\mathrm{PTH}(1-34)$ promoted BMSC migration more effectively at the concentrations of $10,20,50$ and $100 \mathrm{nM}$ than at $1 \mathrm{nM}$, and there were no significant differences between these treatments $(\mathrm{P}>0.05)$. 


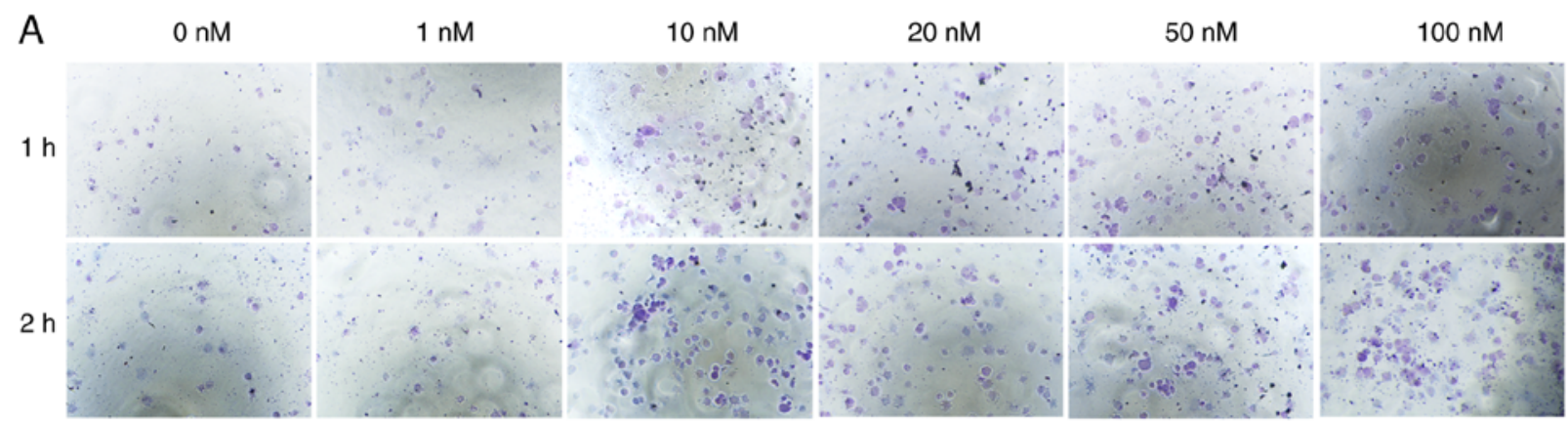

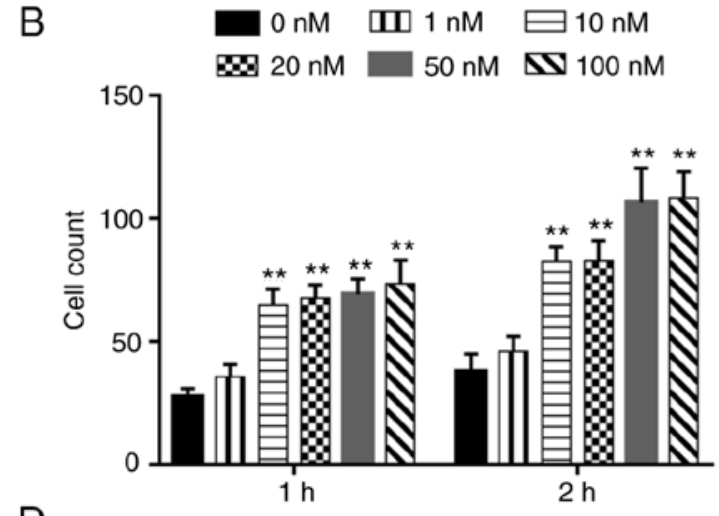

D

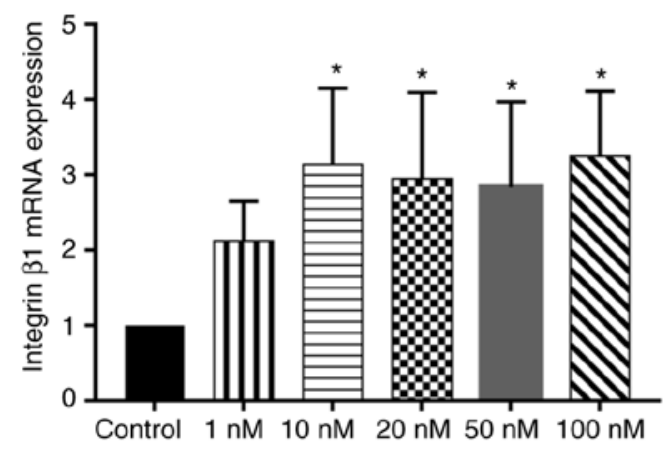

$\mathrm{F}$

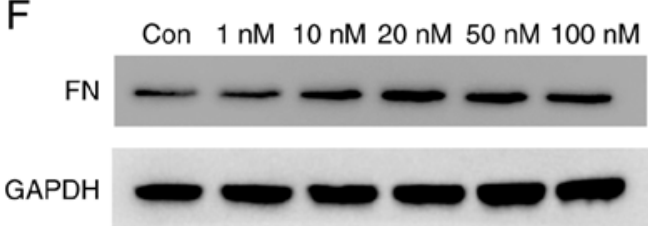

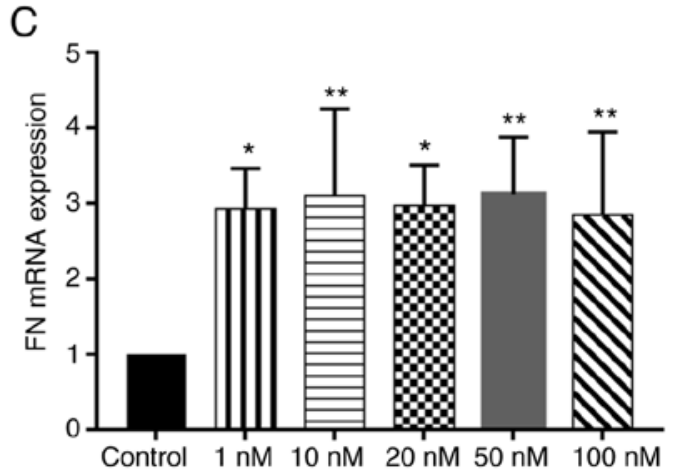

$\mathrm{E}$

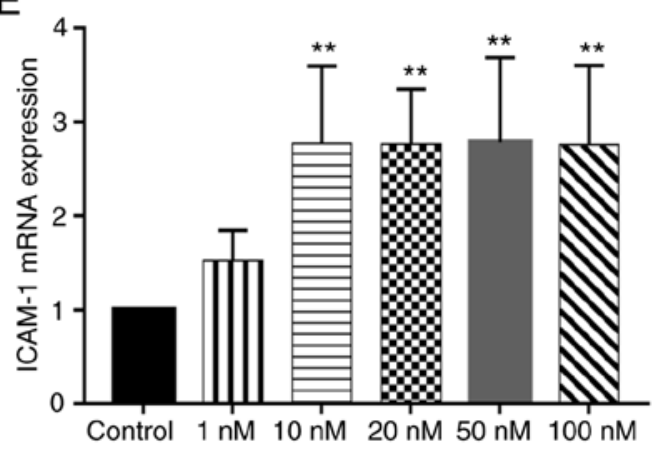

G

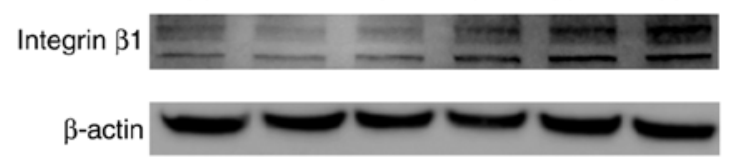

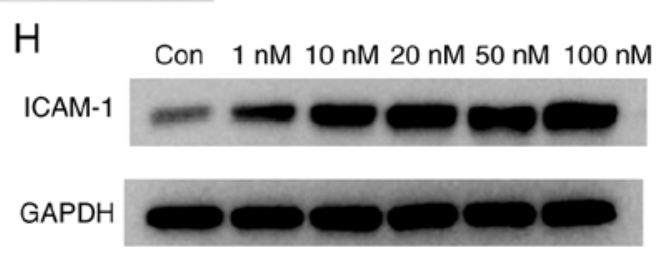

Figure 2. Effect of PTH(1-34) on BMSC adhesion. (A and B) Adhesion analysis of BMSCs pre-treated with various concentrations of PTH(1-34) for 1 or $2 \mathrm{~h}$. Non-adhered cells were removed by washing 3 times with PBS. Giemsa staining was used to visualize adhered cells $(\mathrm{n}=3)$. ${ }^{* *} \mathrm{P}<0.01$ vs. control group. (C-E) mRNA expression of adhesion factors, including FN, integrin $\beta 1$ and ICAM-1, measured by RT-qPCR. Data are the means $\pm \mathrm{SD} ; \mathrm{n}=3$. ${ }^{\mathrm{P}}<0.05$, ${ }^{* *} \mathrm{P}<0.01$ vs. control group. (F-H) Protein expression of ICAM-1, FN and integrin $\beta$ stimulated by various concentrations of PTH(1-34) verified by western blot analysis. BMSCs, bone marrow-derived stromal cells; PTH, parathyroid hormone; ICAM-1, intercellular adhesion molecule 1; FN, fibronectin.

The mRNA expression levels of chemokine receptors were determined by RT-qPCR following the treatment of BMSCs with various concentrations of PTH(1-34). The results revealed that the expression of CXCR4 and CCR2 significantly increased by $\mathrm{PTH}(1-34)$ treatment at various concentrations $(\mathrm{P}<0.05$; Fig. 1E and F). In addition, PTH(1-34) stimulation increased
CXCR4 and CCR2 protein expression (Fig. 1G and H). In summary, these data reveal that $\mathrm{PTH}(1-34)$ can promote the migration of BMSCs.

PTH (1-34) promotes the adhesion of BMSCs. The effects of various concentrations of $\mathrm{PTH}(1-34)$ on the adhesive ability of the 
A

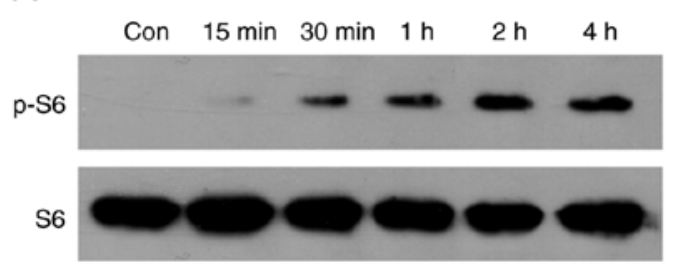

C

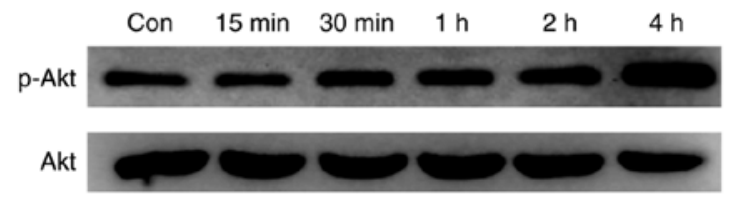

E

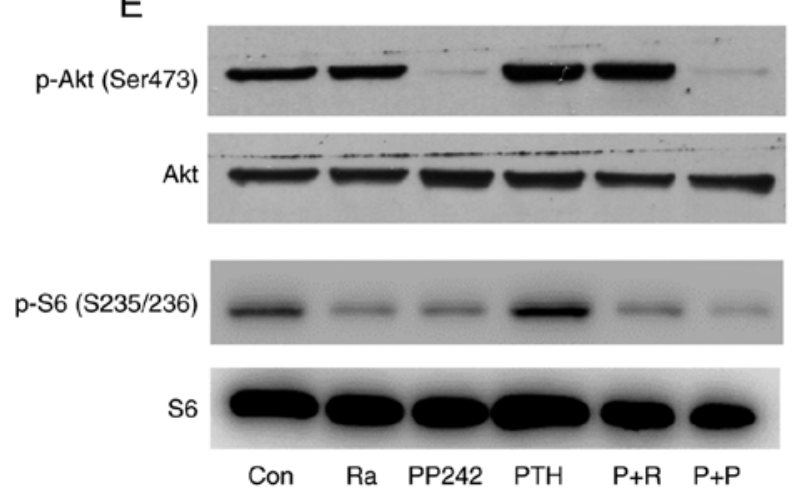

B

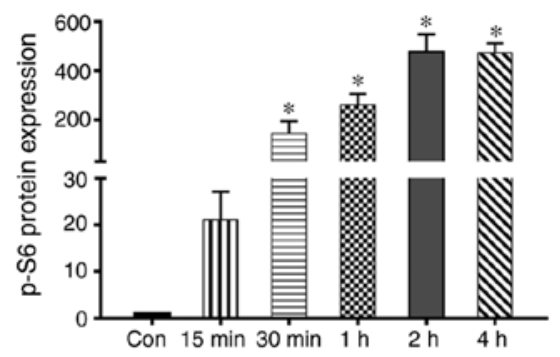

D

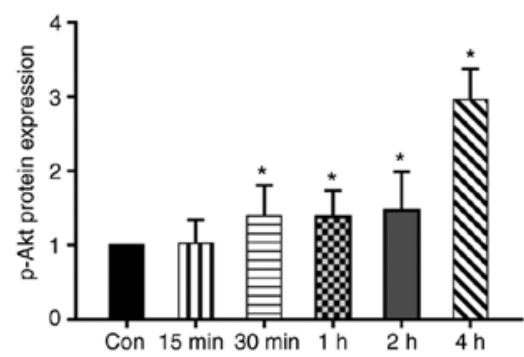

F

$$
\begin{aligned}
& \text { - Control } \infty \text { PTH } \\
& \text { w Rapamycin } \square \text { PTH+Rapamycin } \\
& \square \text { PP242 } \mathbf{~ P T H + P P 2 4 2 ~}
\end{aligned}
$$

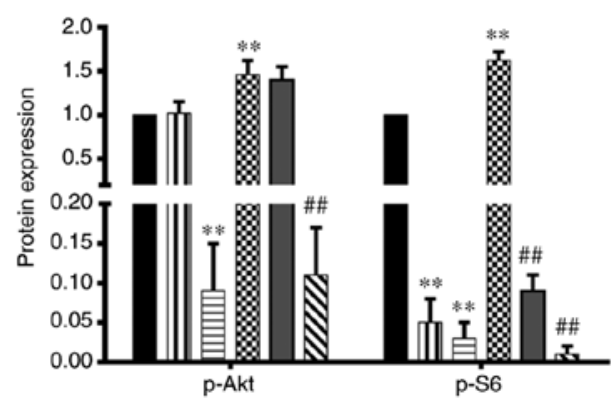

Figure 3. Activation of the mTORC pathway by PTH(1-34) in BMSCs. (A and B) BMSCs incubated with serum-free medium for 12 h (Cont) were treated with $10 \mathrm{nM}$ PTH(1-34) for various periods of time. Whole-cell lysates were acquired for western blot analysis using anti-phospho-Akt (Ser-473) and anti-Akt (Total) antibodies. (C and D) BMSCs incubated with serum-free medium for $12 \mathrm{~h}$ (Cont) were treated with 10 $\mathrm{nM}$ PTH(1-34) for various periods of time. Whole-cell lysates were acquire for western blot analysis using anti-phospho-S6 (Ser235/236) and anti-S6 (Total) antibodies. (E and F) Involvement of mTORC2 in the PTH-dependent phosphorylation of Akt. BMSCs cultured without serum for $12 \mathrm{~h}$ (Cont) were treated with $10 \mathrm{nM}$ PTH (1-34), and 20 nM rapamycin (mTORC1 inhibitor) or $10 \mu \mathrm{M}$ PP242 (mTORC1/2 inhibitor) was added to the medium 15 min prior to PTH(1-34) treatment. Western blot analysis was performed to detect p-S6, S6, Akt and p-Akt (means $\pm \mathrm{SD}$; $\mathrm{n}=3$ ). ${ }^{*} \mathrm{P}<0.05,{ }^{* *} \mathrm{P}<0.01$ vs. control group; ${ }^{\# \#} \mathrm{P}<0.01$ vs. PTH. BMSCs, bone marrow-derived stromal cells; PTH, parathyroid hormone.

BMSCs were examined. Compared with the control treatment, PTH(1-34) significantly increased the number of adherent cells $(\mathrm{P}<0.01)$; however, there were no significant differences between the tested concentrations themselves ( $\mathrm{P}>0.05$; Fig. $2 \mathrm{~A}$ and $\mathrm{B})$.

The mRNA expression levels of key adhesion factors were detected by RT-qPCR after the BMSCs were treated with various concentrations of $\mathrm{PTH}(1-34)$. The results revealed that the expression levels of FN, ICAM- 1 and integrin $\beta 1$ were significantly increased by PTH (1-34) treatment at various concentrations $(\mathrm{P}<0.05$; Fig. $2 \mathrm{C}-\mathrm{E})$. The results of western blot analysis also demonstrated that compared with that observed in the control group, the expression of adhesion factor proteins, including FN, ICAM-1 and integrin $\beta 1$, was markedly increased in the PTH(1-34) stimulation group (Fig. 2F-H).

Activation of the mTORC pathway by PTH(1-34) in BMSCs. However, whether PTH(1-34) can activate the migration and adhesion of BMSCs through the mTORC2 pathway in vitro remain unclear. Therefore, the effects of PTH(1-34) on the activity of the mTORC1 and mTORC2 pathways were investigated and the results were verified by detecting the phosphorylation of S6 on its regulatory Ser235/236 site and the phosphorylation of Akt on its regulatory Ser-473 site. PTH(1-34) an induced increase in Akt Ser-473 phosphorylation and S6 Ser235/236 phosphorylation in the BMSCs. Time course experiments revealed that $\mathrm{PTH}(1-34)$ also induced an increase in the phosphorylation of S6 Ser235/236 in the BMSCs as early as $30 \mathrm{~min}(\mathrm{P}<0.05)$ with the level of $\mathrm{p}-\mathrm{S} 6$ peaking at 2 and $4 \mathrm{~h}$ $(\mathrm{P}<0.05$; Fig. $3 \mathrm{~A}$ and $\mathrm{B})$. On the other hand, time course experiments revealed that $\mathrm{PTH}(1-34)$ increased the phosphorylation of these sites as early as $30 \mathrm{~min}$ in the BMSCs $(\mathrm{P}<0.05)$, and the level of p-Akt was highest at $4 \mathrm{~h}$ following treatment with PTH(1-34) (P<0.01; Fig. 3C and D). Although no marked difference in the level of p-Akt was observed at $30 \mathrm{~min}$, or at 1 and $2 \mathrm{~h}$ following PTH(1-34) treatment, the level was still significantly higher compared to that of the control group $(\mathrm{P}<0.05)$.

The effects of mTORC1 inhibitor, and mTORC $1 / 2$ inhibitor and PTH(1-34) on phosphorylation were then investigated. 

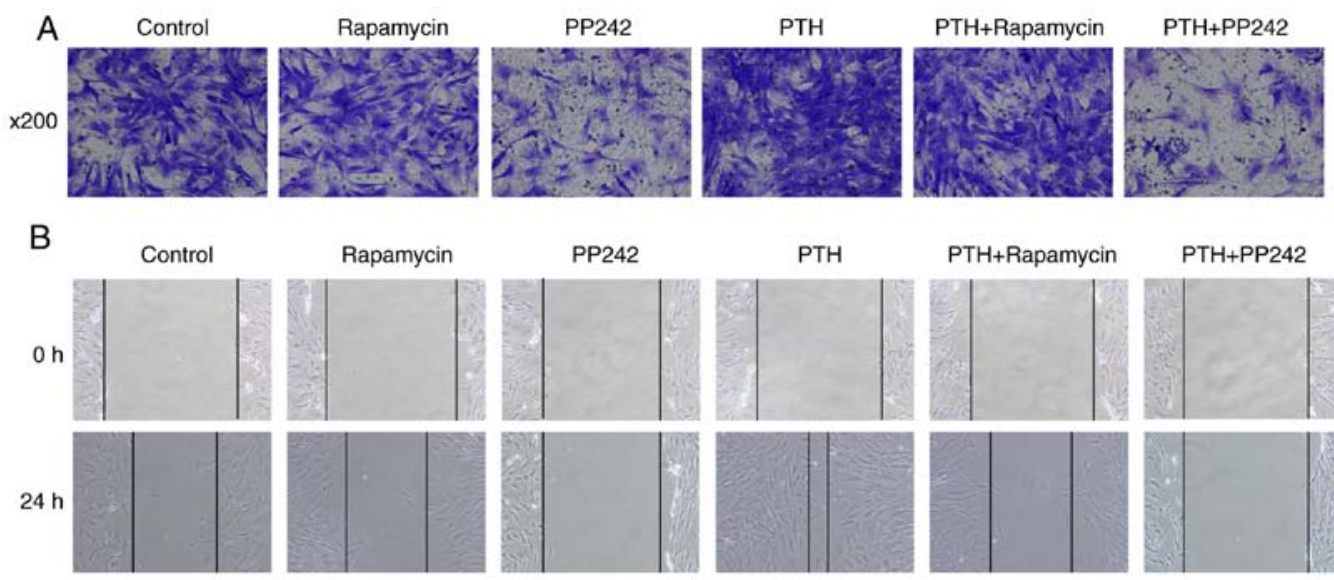

PTH+PP242
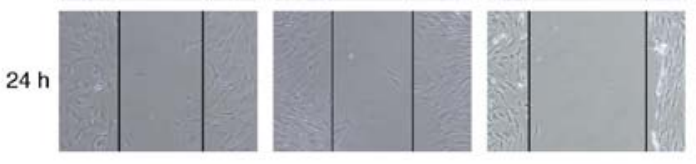

$\mathrm{D}$
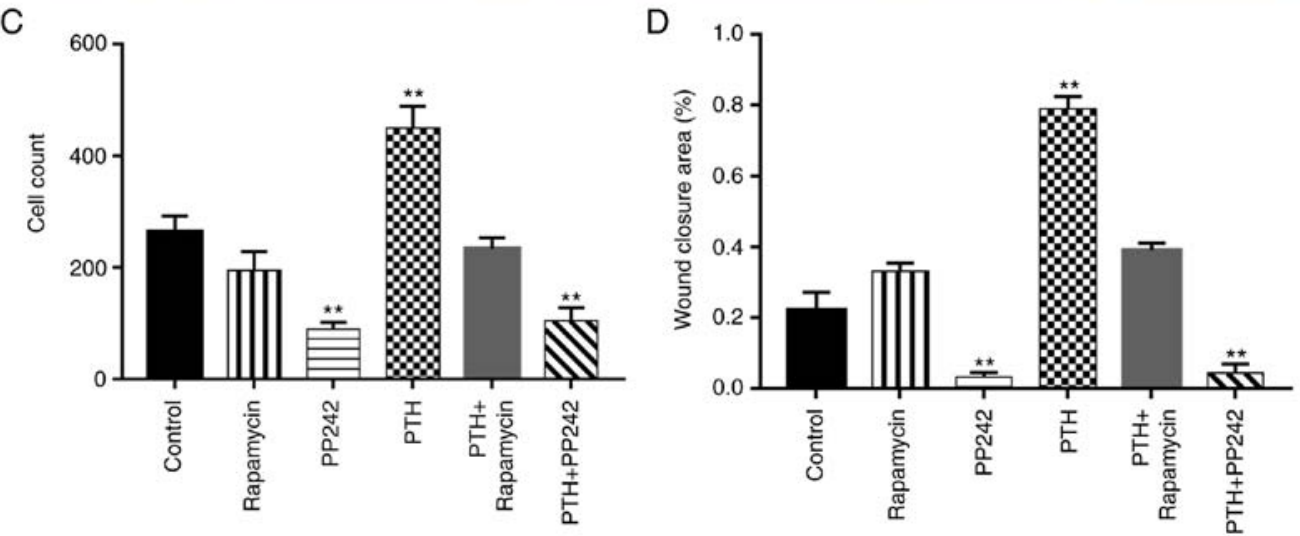

Figure 4. Involvement of the mTORC2 signaling pathway in the PTH-dependent migration and adhesion of BMSCs. (A and C) BMSCs were seeded in the upper chambers of Transwell plates. The bottom wells were loaded with medium alone or medium containing rapamycin and PP242, with or without PTH. The number of cells that migrated to the bottom wells was counted $24 \mathrm{~h}$ later. (B and D) The cell layer was scratched with a $200 \mu 1 \mathrm{sterile}$ pipette tip, and the wound surface area was measured at the 0 and $24 \mathrm{~h}$ timepoints. The results were presented as the percentage of the scratch closure area, ${ }^{* *} \mathrm{P}<0.01$ vs. control group. BMSCs, bone marrow-derived stromal cells; PTH, parathyroid hormone.

The results of western blot analysis revealed that changes in the phosphorylation of these proteins occurred following the pre-treatment of BMSCs with an mTORc1 inhibitor (rapamycin) and an mTORc1/2 inhibitor (PP242). As shown in Fig. 3E and F, compared to the control, rapamycin and PP242 decreased the levels of p-S6 in the BMSCs, and the inhibitory effect of PP242 was more potent than that of rapamycin $(\mathrm{P}<0.01)$. Following stimulation with $\mathrm{PTH}(1-34)$, the levels of p-S6 in the BMSCs were significantly increased. Following the addition of the inhibitors however, the stimulatory effect of PTH(1-34) was inhibited, and the inhibitory effect of PP242 was more potent than that of the other inhibitors $(\mathrm{P}<0.01)$.

Compared to the control group, PP242 also suppressed p-Akt expression, while rapamycin did not $(\mathrm{P}<0.01)$. Following pre-treatment with PTH(1-34), the level of p-Akt in the BMSCs was significantly higher; however, the expression of p-Akt was significantly lower following the addition of PP242 $(\mathrm{P}<0.01)$. Notably, in the rapamycin plus PTH(1-34) treatment group, the expression of p-Akt did not differ from that of the PTH(1-34) treatment group $(\mathrm{P}>0.05)$. These findings suggest that $\mathrm{PTH}$ (1-34) is more likely to function through the mTORC2 pathway.

Involvement of the mTORC2 signaling pathway in the PTH-dependent migration and adhesion of BMSCs. To investigate whether the mTORC2 signaling pathway is involved in PTH-induced BMSC migration, wound healing and Transwell migration assays were performed. Several groups, including the blank group, were treated or not with $10 \mathrm{nM}$ PTH(1-34), with or without pre-treatment with mTORC1 inhibitor (20 $\mathrm{nM}$ rapamycin) or mTORC1/2 inhibitor (10 $\mu \mathrm{M} \mathrm{PP} 242)$. Treatment with PTH(1-34) markedly increased the mobility of the BMSCs $(\mathrm{P}<0.01)$. The mTORC1/2 inhibitor $(\mathrm{PP} 242)$ markedly suppressed $\mathrm{PTH}$-induced cell migration $(\mathrm{P}<0.01$; Fig. 4), while the mTORC1 inhibitor (rapamycin) did not exert any distinct inhibitory on PTH-dependent BMSC migration $(\mathrm{P}>0.05)$. Similar results were observed in the Transwell migration experiments. The $\mathrm{PTH}(1-34)$ treatment group exhibited a notable increase in the number of cells migrating to the lower chamber $(\mathrm{P}<0.01)$, while $\mathrm{PP} 242$ suppressed the effects of PTH(1-34) $(\mathrm{P}<0.01)$. No significant difference was observed between the control group and the rapamycin group $(\mathrm{P}>0.05)$.

The results of RT-qPCR and western blot analyses of the expression of chemokine receptors are shown in Fig. 5A-D. The results revealed that $\mathrm{PTH}(1-34)$ significantly increased the expression of CXCR4 and CCR2 $(\mathrm{P}<0.05)$, while PP242 significantly inhibited the PTH-induced mRNA expression of CXCR4 and CCR2 $(\mathrm{P}<0.05)$. Accordingly, the protein expression of CXCR4 and CCR2 was stimulated by PTH(1-34) $(\mathrm{P}<0.01)$. PP242 decreased the expression of the chemokine receptors $(\mathrm{P}<0.05)$, whereas following treatment with rapamycin, the expression of the marker proteins was not significantly altered compared to that of the control group 
A

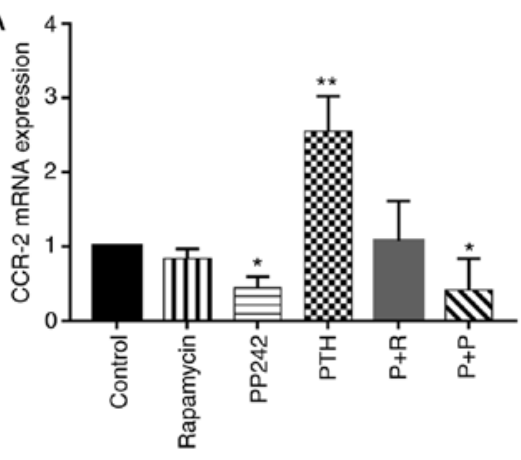

C

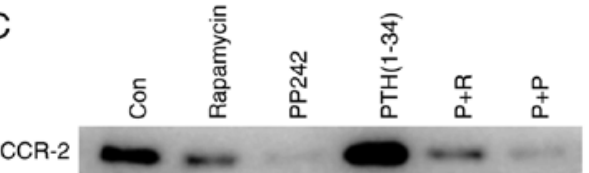

GAPDH

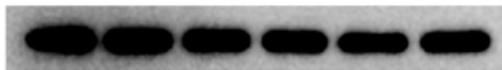

$E$

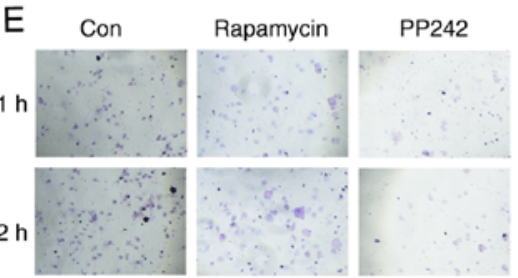

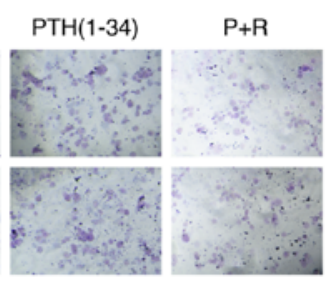

B

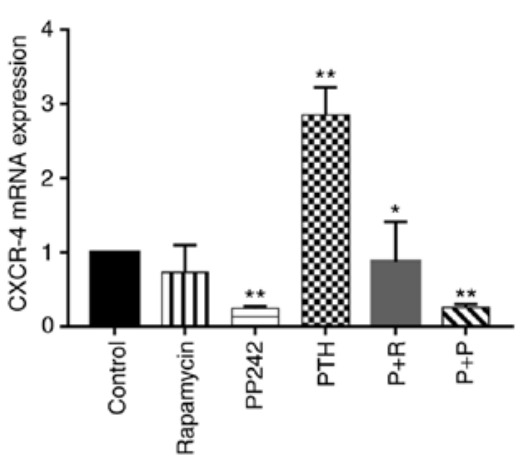

D

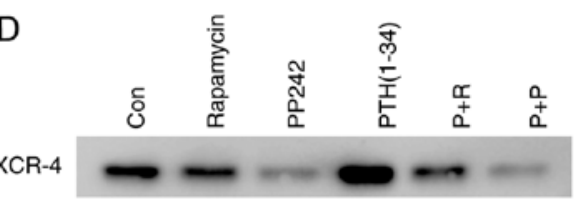

GAPDH

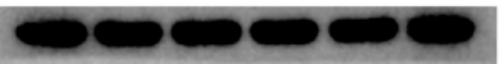

$\mathrm{P}+\mathrm{P}$

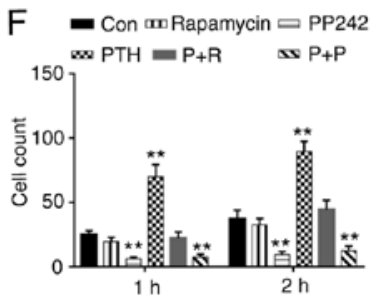

Figure 5. (A and B) mRNA expression of chemokine receptors, including CXCR4 and CCR 2 was measured by RT-qPCR (means \pm SD; $n=3$ ). ${ }^{*} \mathrm{P}<0.05$, ${ }^{* *} \mathrm{P}<0.01$ vs. control group. (C and D) Western blot analysis of CXCR4 and CCR2 expression in BMSCs treated with inhibitors and PTH(1-34). (E and F) Adhesion analysis of BMSCs pretreated with PTH(1-34), rapamycin, PP242, PTH + rapamycin, PTH (1-34) + PP242 and NCs ( $\mathrm{n}=3) .{ }^{* *} \mathrm{P}<0.01$ vs. control group. BMSCs, bone marrow-derived stromal cells; PTH, parathyroid hormone.
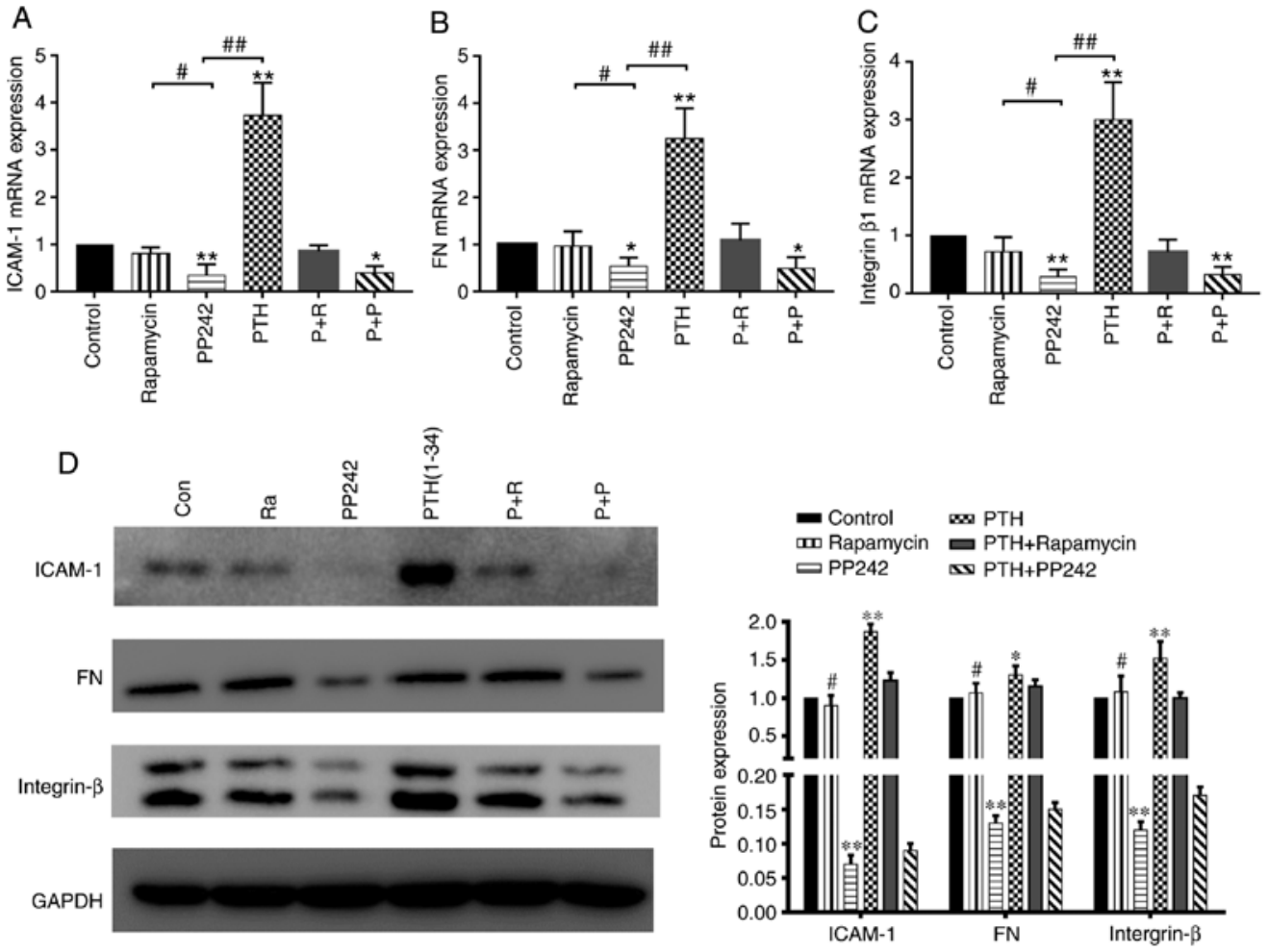

Figure 6. (A-C) mRNA expression of adhesion factors, including ICAM-1, FN and integrin $\beta 1$, in BMSCs treated with inhibitors and PTH was measured by RT-qPCR (means $\pm S D ; n=3$ ). ${ }^{*} \mathrm{P}<0.05,{ }^{* *} \mathrm{P}<0.01$ vs. control group. ${ }^{\prime \prime} \mathrm{P}<0.05$, PP242 vs. rapamycin group ${ }^{\# \#} \mathrm{P}<0.01, \mathrm{PP} 242$ vs. $\mathrm{PTH}$ group. (D) The protein expression of ICAM-1, FN, and integrin $\beta$ in BMSCs treated with inhibitors and PTH was verified by western blot analysis. BMSCs, bone marrow-derived stromal cells; PTH, parathyroid hormone; ICAM-1, intercellular adhesion molecule 1; FN, fibronectin. 

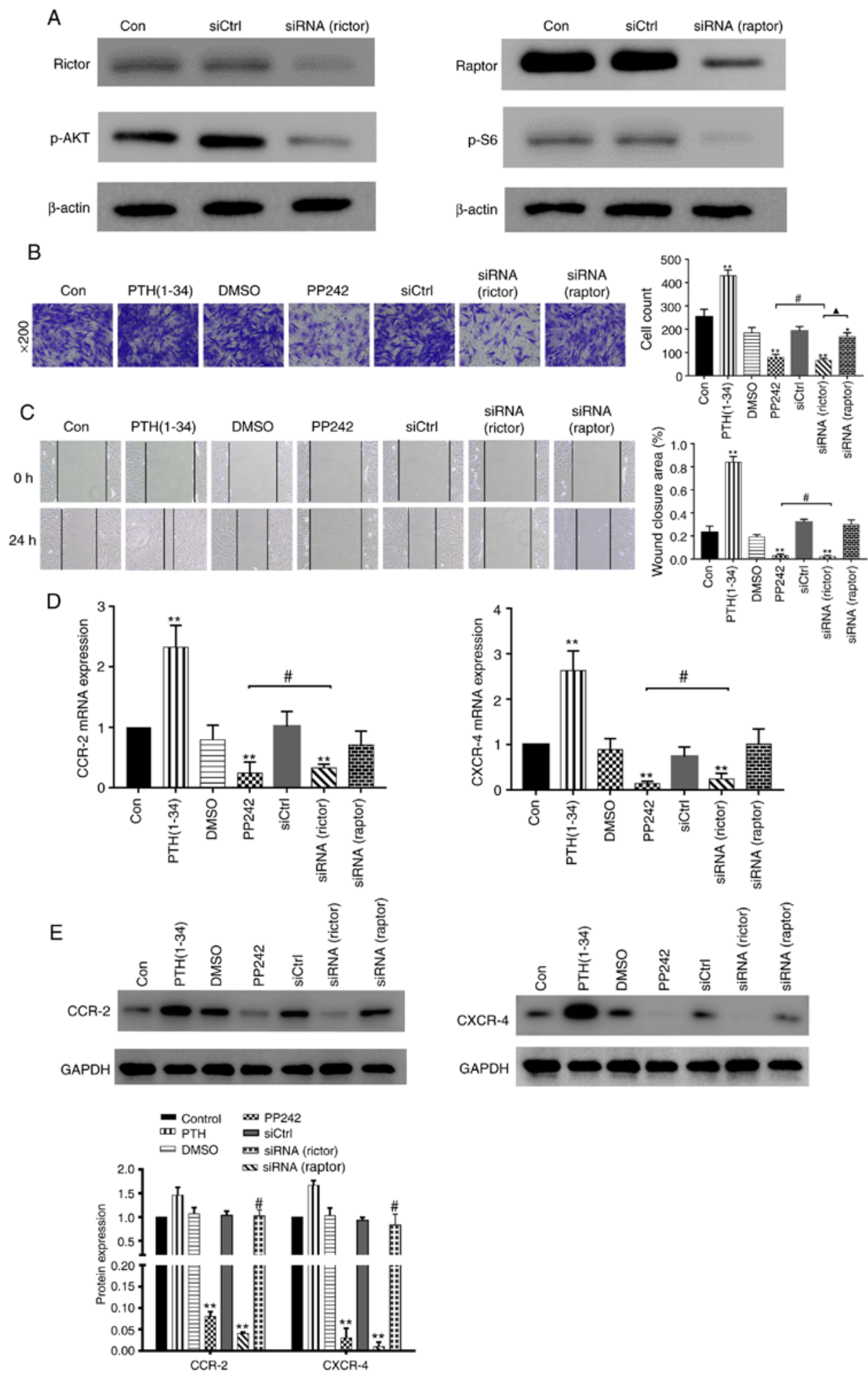

Figure 7. PTH(1-34) mediates BMSC migration and adhesion by targeting rictor. (A) Western blot analysis of rictor and raptor expression and phosphorylation in BMSCs from rictor(-) and raptor(-) cells transfected with lentivirus. (B) Cells in the different groups, including PTH(1-34), DMSO, PP242, siCtrl, siRNA(rictor) and siRNA(raptor), were seeded in the upper chambers of Transwell plates. The number of cells that migrated to the bottom wells was counted 24 h later. ${ }^{*} \mathrm{P}<0.05,{ }^{* *} \mathrm{P}<0.01$ vs. control group. ${ }^{*} \mathrm{P}>0.05$, siRNA(rictor) vs. PP242 group. ${ }^{\wedge} \mathrm{P}<0.05$ siRNA(rictor) vs. siRNA(raptor) group. (C) Results of scratch assays in the different groups, including PTH (1-34), DMSO, PP242, siCtrl, siRNA(rictor), and siRNA(raptor). ${ }^{* *} \mathrm{P}<0.01$ vs. control group. ${ }^{*} \mathrm{P}>0.05$, siRNA(rictor) vs. PP242 group (D) mRNA expression of CXCR4 and CCR2 measured by RT-qPCR. (E) Western blot analysis of CXCR4 and CCR2 expression in the different groups. ${ }^{* *} \mathrm{P}<0.01$ vs. control group, ${ }^{\prime} \mathrm{P}>0.05$, siRNA(rictor) vs. PP242 group. BMSCs, bone marrow-derived stromal cells; PTH, parathyroid hormone.

(P>0.05). These findings suggest that PTH (1-34) activates the migration of BMSCs by increasing the expression of chemokine receptors through the mTORC2 pathway.
To confirm the role of mTORC2 signaling in PTH-induced BMSC adhesion, an adhesion assay was performed to examine the adhesive capacity of each group. Compared with 

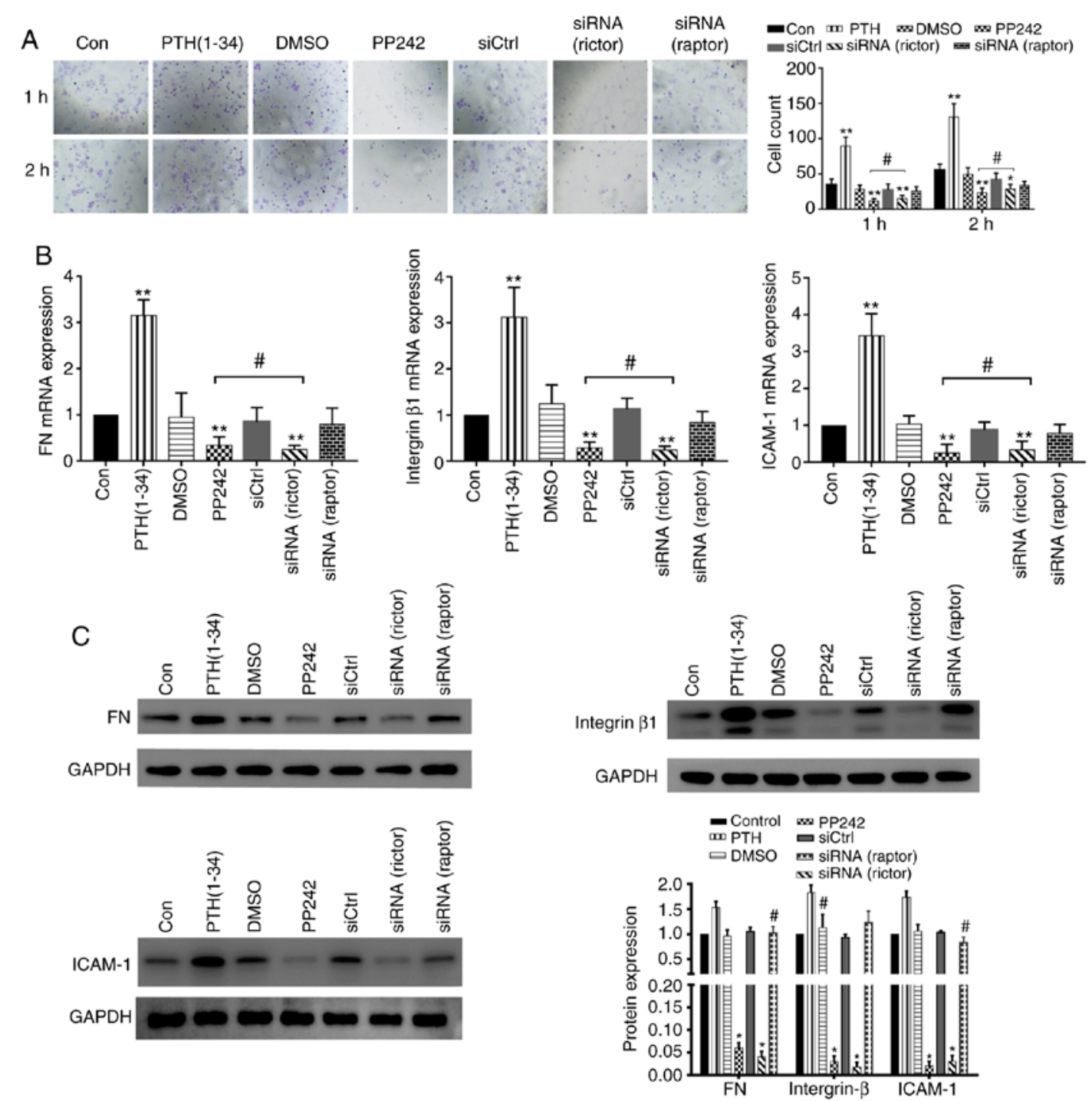

Figure 8. PTH(1-34) mediates BMSC migration and adhesion by targeting rictor. (A) Adhesion analysis of BMSCs from each group. ${ }^{*} \mathrm{P}<0.05,{ }^{* * *} \mathrm{P}<0.01$ vs. control group, ${ }^{\prime} \mathrm{P}>0.05$, siRNA(rictor) vs. PP242 group. (B) mRNA expression of adhesion factors, including ICAM-1, FN and integrin $\beta 1$ (means \pm SD; $\mathrm{n}=3$ ). ${ }^{* *} \mathrm{P}<0.01$ vs. control group, ${ }^{\text {"P }}>0.05$ siRNA(rictor) vs. PP242 group. (C) The protein expression of ICAM-1, FN, and integrin $\beta 1$ was verified by western blot analysis. (means $\pm \mathrm{SD} ; \mathrm{n}=3$ ). ${ }^{\mathrm{P}} \mathrm{P}>0.05$ vs. siRNA(rictor) vs. PP242 group, ${ }^{\prime} \mathrm{P}>0.05$ vs. control group. BMSCs, bone marrow-derived stromal cells; PTH, parathyroid hormone; ICAM-1, intercellular adhesion molecule 1; FN, fibronectin.

the control, stimulation with PTH(1-34) promoted the adhesion of the BMSCs after 1 and $2 \mathrm{~h}$; however, following the addition of PP242, the number of adhered cells was significantly decreased compared with that observed in the PTH group (1 and $2 \mathrm{~h})(\mathrm{P}<0.05$; Fig. 5E and F). RT-qPCR analysis of the expression of adhesion factors is shown in Fig. 6A-C. The mRNA expression of key adhesion factors in BMSCs was induced by the intermittent use of $\mathrm{PTH}(1-34)(\mathrm{P}<0.05)$. PP242 exerted a more potent inhibitory effect on the expression of ICAM-1, FN and integrin $\beta 1$ than rapamycin $(\mathrm{P}<0.05)$ or the $\mathrm{PTH}(1-34)$ group $(\mathrm{P}<0.01)$. The results of western blot analysis of ICAM-1, FN and integrin $\beta 1$ expression in all groups are shown in Fig. 6D. Following stimulation with PTH(1-34), the expression of adhesion factors in the BMSCs was significantly increased, whereas it was significantly downregulated following pre-treatment with PP242 $(\mathrm{P}<0.01)$. However, compared to the control treatment, rapamycin exerted minimal effects on the expression of adhesion factors $(\mathrm{P}>0.05)$. Therefore, the above-mentioned results suggest that the mTORC2 signaling pathway is involved in the PTH-induced adhesion of BMSCs.

BMSCs lacking rictor rather than raptor are insensitive to the effects of PTH(1-34). Subsequently, the present study wished to determine whether rictor, which is crucial for the kinase activity of mTORC2, is essential for the PTH-induced BMSC migration and adhesion via lentiviral silencing. As was expected, the lentiviruses downregulated rictor/mTORC2 signaling and the phosphorylation of Akt (S473) or raptor/mTORC1 pathway and the phosphorylation of S6 (Ser235/236) (Fig. 7A). In the wound healing and Transwell assays (Fig. 7B and C), the intermittent use of PTH(1-34) significantly increased the mobility of the BMSCs compared to that observed in the negative control groups $(\mathrm{P}<0.01)$. The results revealed that PP242 markedly suppressed BMSC migration $(\mathrm{P}<0.01)$, similar to that observed in the siRNA(rictor) group $(\mathrm{P}>0.05)$. Moreover, the migratory ability of the siRNA(raptor)-treated BMSCs differed significantly 
from that observed in the siRNA(rictor) group $(\mathrm{P}<0.05)$. For the gene expression analysis, the levels of the chemokine receptors in the siRNA(rictor) group were significantly lower than those in the control group $(\mathrm{P}<0.01)$, but were similar to those observed in the PP242 group (P>0.05) (Fig. 7D). By contrast, no significant differences were observed between the siRNA(raptor) group and the control group $(\mathrm{P}>0.05)$. Accordingly, the protein levels of CXCR4 and CCR2 in the PP242 and siRNA(rictor) groups were significantly decreased compared to those observed in the control group $(\mathrm{P}<0.01)$, whereas the levels of these proteins in the siRNA(raptor) BMSC group were similar to those detected in the control group ( $\mathrm{P}>0.05$; Fig. 7E). The above-mentioned results suggest that rictor, the key component of mTORC2, is involved in the PTH-induced migration of BMSCs.

An adhesion assay was also performed to examine the adhesive capacity of each group. Compared with the control group, the adhesive ability of the cells in the PP242 pre-treatment and siRNA(rictor) groups was significantly decreased after 1 and $2 \mathrm{~h}(\mathrm{P}<0.01)$, while the numbers of adhered cells in the siRNA(raptor) group were similar to those detected in the negative control group ( 1 and $2 \mathrm{~h}$ ) ( $\mathrm{P}>0.05$; Fig. $8 \mathrm{~A})$. The results of RT-qPCR analysis revealed that the adhesion factor mRNA levels in the siRNA(rictor) and the PP242 group were similar $(\mathrm{P}>0.05)$. By contrast, the mRNA expression levels exhibited no significant differences between the siRNA(raptor) group and the control group ( $\mathrm{P}>0.05$; Fig. 8B). The protein expression of key adhesion factors in the BMSCs from the different treatment groups was examined by western blot analysis. The protein levels of ICAM-1, FN and integrin $\beta 1$, in the PP242 and the siRNA(rictor) group were similar ( $\mathrm{P}>0.05$ ), whereas those detected in the siRNA(raptor) BMSC group were similar to those observed in the control group (P>0.05; Fig. 8C). Taken together, these results suggest that PTH (1-34) directly targets rictor to affect BMSC migration and adhesion.

\section{Discussion}

Implant-bone integration refers to the structural and functional connection between the bone surface and an implant (26). A series of intracellular and extracellular responses are involved in the formation and remodeling phases of bone healing $(27,28)$. The active ingrowth of the bone to the implant surface is the most important aspect of bone integration. The migration and adhesion of bone marrow MSCs and osteoblasts to the surface are pivotal aspects of ingrowth $(3,6)$, as both of these processes are required for osteogenic differentiation and bone mineralization. Thus, successful integration depends on these biological processes.

A series of studies have established that the intermittent administration of PTH can improve osteogenic differentiation and bone mineralization $(10,29)$. Other studies have demonstrated that PTH(1-34) can enhance bone regeneration around the implant and improve the healing rate of the implant-bone interface in the bone defect area (30). However, the mechanistic aspects of this process, particularly the regulation of BMSC migration and adhesion, are not yet fully understood. In the present study, it was observed that PTH(1-34) promoted not only the migratory, but also the adhesive ability of the
BMSCs. It was also demonstrated that the mTORC2 pathway can be activated by PTH(1-34), and that rictor is an important contributor to this process. It is considered that this new mechanism may aid in the elucidation of the role of PTH in promoting bone-implant integration.

It has recently been demonstrated that PTH can significantly enhance MSC migration to the lumbar region, where MSCs differentiate into bone-forming cells (31). SDF-1 belongs to the CXC chemokine family and exerts multiple biological functions. The previous study by Du et al (12) suggested that the combination of PTH and SDF-1 $\alpha$ plays an essential role in the migration and osteogenic differentiation of human PDLSCs. In addition, the SDF-1/CXCR4 axis can mediate the recruitment of MSCs to the periodontal defect (32). It has been reported that MCP-1 can induce MSC migration in vitro, and that the application of PTH can mobilize endogenous BMSCs/progenitors as an effective and feasible regeneration treatment for patients with ischemic stroke (33). In addition, it has been demonstrated that MCP-1 migration is mediated by CCR2. Ryan et al examined the effects of MCP-1 activation, and demonstrated that it is important for stem cell migration (34). In the present study, scratch wound healing and Transwell migration assays were performed to examine the effects of PTH on the migration of BMSCs. It was observed that PTH(1-34) upregulated the expression of CXCR4 and CCR2. The specific elimination of rictor and the application of inhibitors significantly suppressed the effects of PTH. These data indicate that $\mathrm{PTH}(1-34)$ exerts a stimulatory effect on BMSC migration through the rictor/mTORC2 signaling pathway.

The adhesibve ability is one factor in the first stage of the cell-material interaction. MSCs are sensitive to substrate properties, and adhesion determines the proliferation and differentiation ability of cells after contact with implants. The expression of adhesion factors, such as ICAM-1, FN and integrin $\beta 1$, is associated with the adhesive capacity of cells $(35,36)$. Davies and Chambers (37) suggested that the adhesion of such stromal precursors, termed colony-forming units-fibroblastic (CFU-F) to bone may be an early event in the bone response to PTH. Lee et al (38) established a flexor digitorum longus (FDL) tendon repair model in $\mathrm{C} 57 \mathrm{Bl} / 6 \mathrm{~J}$ mice to evaluate adhesion formation. They observed that PTH accelerated the deposition of reparative tissue and increased cell adhesion. Furthermore, the ICAM-1-mediated cell-to-cell adhesion of osteoblast and osteoclast precursors can be stimulated by PTH (39). In the present study, cell adhesion assays were performed to examine the effects of PTH(1-34) on the adhesion of BMSCs, and the data revealed that $\mathrm{PTH}(1-34)$ promoted BMSC adherence to the surface. In addition, the adhesive ability of inhibitor-treated and rictor(-) cells was significantly decreased. The expression of ICAM-1, FN and integrin $\beta 1$ in the different BMSC groups was assessed by western blot analysis and mRNA expression analyses following treatment with PTH(1-34), as our results showed. The results further demonstrated that the expression of adhesion factors was significantly upregulated by PTH(1-34), suggesting that PTH(1-34) enhances the adhesion of BMSCs through the rictor/mTORC2 signaling pathway.

The rictor/mTORC2 pathway is involved in various biological processes, such as cell migration, adhesion and 
cytoskeletal reorganization. Wang et al (16) analyzed overall proteome changes in cells in which rictor was knocked down and found that rictor was highly involved in cell migration and adhesion. Subsequently, assays were performed to determine whether the migratory and adhesive ability of cells in which rictor was knocked down was significantly reduced. PTH can induce insulin-like growth factor (Igf) signaling, and the metabolic effects of Igf depend on the activation of mTORC2 (40). Additionally, Chantaravisoot et al (41) suggested that the mTORC1/2 inhibitor PP242, but not rapamycin attenuated focal adhesion formation and cell migration in U87vIII glioblastoma cells. These results were similar to those obtained in the present study. The results suggested that rapamycin partially reversed the $\mathrm{PTH}$-induced migration and adhesion of BMSC cells. The mTORC 2 complex was originally considered to be rapamycin-insensitive; however, some researchers have found that chronic treatment with rapamycin can suppress mTORC2 activity and disrupt mTORC2 assembly (42). Rapamycin has been demonstrated to mediate rictor dephosphorylation in a time- and concentration-dependent manner, at physiologically relevant rapamycin concentrations (43). Wang et al (44) found that prolonged rapamycin pre-treatment reduced the expression of tumor necrosis factor (TNF)-induced vascular cell adhesion molecule-1 by inhibiting mTORC2, thereby reducing the effect of TNF-treated endothelial cells on capturing leukocytes. Lamming et al (45) suggested that chronic rapamycin treatment impaired the insulin-mediated suppression of hepatic gluconeogenesis via the disruption of the mTORC2 in vivo. However, the underlying mechanisms warrant further investigation.

The findings of the present study suggested that $\mathrm{PTH}(1-34)$ significantly increased the level of p-Akt, and that mTORC1/2 inhibitors and rictor silencing decreased the p-Akt levels. As rapamycin predominantly suppressed $\mathrm{mTORC1}$, the inhibition of mTORC2 appeared to account for the effects of PP242. Furthermore, blocking the rictor/mTORC2 signaling pathway by PP242 and reducing the rictor levels clearly suppressed the migration and adhesion of BMSCS. The above-mentioned data suggest that the rictor/mTORC2 signaling pathway may play important roles in the PTH-induced cell migration and adhesion of BMSCs.

In spite of the large amount of research performed to demonstrate the original hypothesis, the present study has several limitations. Rather than using more genetically applicable mice or more clinically translatable human cellular models, BMSCs from rats were used in the present study. Thus, additional in vitro and in vivo studies are required to further explore the molecular mechanisms of this pathway.

In conclusion, the results of the present study demonstrate that $\mathrm{PTH}(1-34)$ promotes BMSC migration and adhesion in vitro, and that the downregulation of the rictor/mTORC2 pathway is involved in mediating the effects of $\mathrm{PTH}(1-34)$. This pathway may be a mechanism through which PTH promotes the bone integration of implants and may provide a novel target for future experimental and clinical studies for the prevention of implant loosening.

\section{Acknowledgements}

Not applicable.

\section{Funding}

The present study was supported by grants from the Natural Science Foundation of China (no. 31570976), and the Science and Technology Program of Guangzhou, China (no. 201604020148). The content is solely the responsibility of the authors and does not necessarily represent the official views of the Natural Science Foundation of China.

\section{Availability of data and materials}

All data generated or analyzed during this study are included in this published article or are available from the corresponding author on reasonable request.

\section{Authors' contributions}

$\mathrm{BC}$ conceived and designed the study. ZL, XB, XZ and TL performed the experiments. $\mathrm{AM}$ and $\mathrm{BC}$ analyzed and interpreted the data and wrote the manuscript. All authors read and approved the final manuscript.

\section{Ethics approval and consent to participate}

The present study was approved by the Animal Care Committee of Sun Yat-Sen University [no. (2014)52] and was performed in accordance with the guidelines for the use of laboratory animals.

\section{Patient consent for publication}

Not applicable.

\section{Competing interests}

The authors declare that they have no competing interests.

\section{References}

1. Ponnusamy KE, Iyer S, Gupta G and Khanna AJ: Instrumentation of the osteoporotic spine: Biomechanical and clinical considerations. Spine J 11: 54-63, 2011.

2. Dvorak G, Arnhart S, Heuberer C, Huber G, Watzek R and Gruber R: Peri-implantitis and late implant failures in postmenopausal women: A cross-sectional study. J Clin Periodontol 38: 950-955, 2011.

3. Cameron P, Travers C, Chander T, Buckland C, Campion B and Noble B: Directed osteogenic differentiation of human mesenchymal stem/precursor cells on silicate substituted calcium phosphate. J Biomed Mater Res A 101: 13-22, 2013.

4. Mavrogenis AF, Dimitriou R, Parvizi J and Babis GC: Biology of implant osseointegration. J Musculoskelet Neuronal Interact 9: 61-71, 2009.

5. Davies JE: Understanding peri-implant endosseous healing. J Dent Educ 67: 932-949, 2003

6. Olivares-Navarrete R, Hyzy SL, Hutton DL, Erdman CP, Wieland M, Boyan BD and Schwartz Z: Direct and indirect effects of microstructured titanium substrates on the induction of mesenchymal stem cell differentiation towards the osteoblast lineage. Biomaterials 31: 2728-2735, 2010.

7. Puleo DA and Nanci A: Understanding and controlling the bone-implant interface. Biomaterials 20: 2311-2321, 1999.

8. Özdal-Kurt F, Tuğlu I, Vatansever HS, Tong S, Şen BH and Deliloğlu-Gürhan SI: The effect of different implant biomaterials on the behavior of canine bone marrow stromal cells during their differentiation into osteoblasts. Biotech Histochem 91: 412-422, 2016. 
9. Kaback LA, Soung DY, Naik A, Geneau G, Schwarz EM, Rosier RN, O'Keefe RJ and Drissi H: Teriparatide (1-34 human PTH) regulation of osterix during fracture repair. J Cell Biochem 105: 219-226, 2008.

10. Jiang L, Zhang W, Wei L, Zhou Q, Yang G, Qian N, Tang Y, Gao Y and Jiang X: Early effects of parathyroid hormone on vascularized bone regeneration and implant osseointegration in aged rats. Biomaterials 179: 15-28, 2018.

11. Ohkawa Y, Tokunaga $\mathrm{K}$ and Endo $\mathrm{N}$ : Intermittent administration of human parathyroid hormone (1-34) increases new bone formation on the interface of hydroxyapatitecoated titanium rods implanted into ovariectomized rat femora. J Orthop Sci 13: 533-542, 2008.

12. Du L, Feng R and Ge S: PTH/SDF- $1 \alpha$ cotherapy promotes proliferation, migration and osteogenic differentiation of human periodontal ligament stem cells. Cell Prolif 49: 599-608, 2016.

13. Sengupta S, Peterson TR and Sabatini DM: Regulation of the mTOR complex 1 pathway by nutrients, growth factors, and stress. Mol Cell 40: 310-322, 2010.

14. Zoncu R, Efeyan A and Sabatini DM: mTOR: From growth signal integration to cancer, diabetes and ageing. Nat Rev Mol Cell Biol 12: 21-35, 2011.

15. Diz-Muñoz A, Thurley K, Chintamen S, Altschuler SJ, Wu LF, Fletcher DA and Weiner OD: Membrane tension acts through PLD2 and mTORC2 to limit actin network assembly during neutrophil migration. PLoS Biol 14: e1002474, 2016.

16. Wang H, Shao X, He Q, Wang C, Xia L, Yue D, Qin G, Jia C and Chen R: Quantitative proteomics implicates rictor/mTORC2 in cell adhesion. J Proteome Res 17: 3360-3369, 2018.

17. Huang L, Zhang Y, Xu C, Gu X, Niu L, Wang J, Sun X, Bai X, Xuan X, Li Q, et al: Rictor positively regulates B cell receptor signaling by modulating actin reorganization via ezrin. PLoS Biol 15: e2001750, 2017.

18. Sarbassov DD, Ali SM, Kim DH, Guertin DA, Latek RA, Erdjument-Bromage H, Tempst P and Sabatini DM: Rictor, a novel binding partner of $\mathrm{mTOR}$, defines a rapamycin-insensitive and raptor-independent pathway that regulates the cytoskeleton. Curr Biol 14: 1296-1302, 2004.

19. Sen B, Xie Z, Case N, Thompson WR, Uze G, Styner M and Rubin J: mTORC2 regulates mechanically induced cytoskeletal reorganization and lineage selection in marrow-derived mesenchymal stem cells. J Bone Miner Res 29: 78-89, 2014.

20. Gulhati P, Bowen KA, Liu J, Stevens PD, Rychahou PG, Chen M, Lee EY, Weiss HL, O'Connor KL, Gao T and Evers BM: mTORC1 and mTORC2 regulate EMT, motility, and metastasis of colorectal cancer via RhoA and Racl signaling pathways. Cancer Res 71: 3246-3256, 2011.

21. Wang X, Lai P, Zhang Z, Huang M, Wang L, Yin M, Jin D, Zhou R and Bai X: Targeted inhibition of mTORC2 prevents osteosarcoma cell migration and promotes apoptosis. Oncol Rep 32: 382-388, 2014.

22. Hau AM, Leivo MZ, Gilder AS, Hu JJ, Gonias SL and Hansel DE: mTORC2 activation is regulated by the urokinase receptor (uPAR) in bladder cancer. Cell Signal 29: 96-106, 2017.

23. Maniatopoulos C, Sodek J and Melcher AH: Bone formation in vitro by stromal cells obtained from bone marrow of young adult rats. Cell Tissue Res 254: 317-330, 1988

24. Smajilagić A, Aljičević M, Redžić A,Filipović S and Lagumdžija A Rat bone marrow stem cells isolation and culture as a bone formative experimental system. Bosn J Basic Med Sci 13: 27-30, 2013.

25. Livak KJ and Schmittgen TD: Analysis of relative gene expression data using real-time quantitative PCR and the 2(-Delta Delta C(T)) method. Methods 25: 402-408, 2001

26. Alghamdi HS, Bosco R, Both SK, Iafisco M, Leeuwenburgh SC, Jansen JA and van den Beucken JJ: Synergistic effects of bisphosphonate and calcium phosphate nanoparticles on peri-implant bone responses in osteoporotic rats. Biomaterials 35: 5482-5490, 2014.

27. Zhu D, Su Y, Young ML, Ma J, Zheng Y and Tang L: Biological responses and mechanisms of human bone marrow mesenchymal stem cells to $\mathrm{Zn}$ and $\mathrm{Mg}$ biomaterials. ACS Appl Mater Interfaces 9: 27453-27461, 2017.

28. Petrie TA, Raynor JE, Dumbauld DW, Lee TT, Jagtap S Templeman KL, Collard DM and Garcia AJ: Multivalent integrin-specific ligands enhance tissue healing and biomaterial integration. Sci Transl Med 2: 45r-60r, 2010.

29. Misof BM, Roschger P, Dempster DW, Zhou H, Bilezikian JP, Klaushofer K and Rubin MR: PTH(1-84) administration in hypoparathyroidism transiently reduces bone matrix mineralization. J Bone Miner Res 31: 180-189, 2016.
30. Morgan EF, Mason ZD, Bishop G, Davis AD, Wigner NA, Gerstenfeld LC and Einhorn TA: Combined effects of recombinant human BMP-7 (rhBMP-7) and parathyroid hormone (1-34) in metaphyseal bone healing. Bone 43: 1031-1038, 2008.

31. Sheyn D, Shapiro G, Tawackoli W, Jun DS, Koh Y, Kang KB, Su S, Da X, Ben-David S, Bez M, et al: PTH induces systemically administered mesenchymal stem cells to migrate to and regenerate spine injuries. Mol Ther 24: 318-330, 2016.

32. Kitaori $\mathrm{T}$, Ito $\mathrm{H}$, Schwarz ME, Tsutsumi R, Yoshitomi $\mathrm{H}$, Oishi S, Nakano M, Fujii N, Nagasawa T and Nakamura T: Stromal cell-derived factor 1/CXCR4 signaling is critical for the recruitment of mesenchymal stem cells to the fracture site during skeletal repair in a mouse model. Arthritis Rheum 60: 813-823, 2009.

33. Wang LL, Chen D, Lee J, Gu X, Alaaeddine G, Li J, Wei L and Yu SP: Mobilization of endogenous bone marrow derived endothelial progenitor cells and therapeutic potential of parathyroid hormone after ischemic stroke in mice. PLoS One 9: e87284, 2014.

34. Ryan CM, Brown JA, Bourke E, Prendergast M, Kavanagh C, Liu Z, Owens P, Shaw G, Kolch W, O'Brien T and Barry FP: ROCK activity and the G $\beta \mathrm{g}$ complex mediate chemotactic migration of mouse bone marrow-derived stromal cells. Stem Cell Res Ther 6: 136, 2015.

35. Yang L, Froio RM, Sciuto TE, Dvorak AM, Alon R and Luscinskas W: ICAM-1 regulates neutrophil adhesion and transcellular migration of TNF-alpha-activated vascular endothelium under flow. Blood 106: 584-592, 2005.

36. Pendegrass CJ, El-Husseiny M and Blunn GW: The development of fibronectin-functionalised hydroxyapatite coatings to improve dermal fibroblast attachment in vitro. J Bone Joint Surg Br 94: 564-569, 2012.

37. Davies T and Chambers TJ: Parathyroid hormone activates adhesion in bone marrow stromal precursor cells. J Endocrinol 180 505-513, 2004

38. Lee DJ, Southgate RD, Farhat YM, Loiselle AE, Hammert WC, Awad HA and O'Keefe RJ: Parathyroid hormone 1-34 enhances extracellular matrix deposition and organization during flexor tendon repair. J Orthop Res 33: 17-24, 2015.

39. Okada Y, Morimoto I, Ura K, Watanabe K, Eto S, Kumegawa M, Raisz L, Pilbeam C and Tanaka Y: Cell-to-cell adhesion via intercellular adhesion molecule-1 and leukocyte function-associated antigen-1 pathway is involved in 1alpha, 25(OH)2D3, PTH and IL-lalpha-induced osteoclast differentiation and bone resorption. Endocr J 49: 483-495, 2002.

40. Yin Y, Hua H, Li M, Liu S, Kong Q, Shao T, Wang J, Luo Y, Wang Q, Luo T and Jiang Y: mTORC2 promotes type I insulin-like growth factor receptor and insulin receptor activation through the tyrosine kinase activity of mTOR. Cell Res 26: 46-65, 2016.

41. Chantaravisoot N, Wongkongkathep P, Loo JA, Mischel PS and Tamanoi F: Significance of filamin A in mTORC2 function in glioblastoma. Mol Cancer 14: 127, 2015.

42. Rosner $M$ and Hengstschläger $M$ : Cytoplasmic and nuclear distribution of the protein complexes mTORC1 and mTORC2: Rapamycin triggers dephosphorylation and delocalization of the mTORC2 components rictor and sin1. Hum Mol Genet 17: 2934-2948, 2008.

43. Akcakanat A, Singh G, Hung MC and Meric-Bernstam F: Rapamycin regulates the phosphorylation of rictor. Biochem Biophys Res Commun 362: 330-333, 2007.

44. Wang C, Qin L, Manes TD, Kirkiles-Smith NC, Tellides G and Pober JS: Rapamycin antagonizes TNF induction of VCAM-1 on endothelial cells by inhibiting mTORC2. J Exp Med 211: 395-404, 2014.

45. Lamming DW, Ye L, Katajisto P, Goncalves MD, Saitoh M, Stevens DM, Davis JG, Salmon AB, Richardson A, A hima R, et al: Rapamycin-induced insulin resistance is mediated by mTORC2 loss and uncoupled from longevity. Science 335: 1638-1643, 2012.

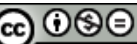

This work is licensed under a Creative Commons Attribution-NonCommercial-NoDerivatives 4.0 International (CC BY-NC-ND 4.0) License. 